\title{
Predictive Activity Modeling of 2-Substituent-1H-Benzimidazole-4- Carboxamide Derivatives against Enteroviruses using QSAR Approach
}

\section{Mukesh C Sharma}

School of Pharmacy, Devi Ahilya University, Takshila Campus, Khandwa Road, Indore-452 001, Madhya Pradesh, India

\begin{abstract}
The present study was focused on development of the potential compound containing 2-substituent- $1 \mathrm{H}$ benzimidazole-4-carboxamide derivatives against enteroviruses using QSAR studies. We discussed the twodimensional QSAR studies of 2-substituent-1H-benzimidazole-4-carboxamide analogues to elucidate the structural properties required for enteroviruses activity. The 2D-QSAR studies were performed using multiple linear regressions, giving square of correlation coefficient $(\mathrm{r} 2)=0.7458$, cross validated squared correlation coefficient $(\mathrm{q} 2)=0.7128$ and predictable ability (pred r2) $=0.7092$. The present study reveals that presence of less bulky group at R1 position of benzimidazole scaffold increase the enteroviruses activity. We hope that the current study provides better insight into the designing and development of more potent benzimidazole-4-carboxamide inhibitors as enteroviruses drug in the future.
\end{abstract}

Keywords: Benzimidazole; Enteroviruses; 2D-QSAR; Multiple linear regressions

\section{Introduction}

Antiviral drugs are urgently needed for the treatment of acute and chronic diseases caused by enteroviruses such as coxsackievirus B3 (CVB3). Enteroviruses are members of the picornavirus family, a large and diverse group of small RNA viruses characterized by a single positive-strand genomic RNA. Enteroviruses affect millions of people worldwide each year, and cause many serious diseases as poliomyelitis, nonspecific febrile illness, aseptic meningitis, pleurodynia, myocarditis [1]. Enteroviruses were a genus of $(+)$ ssRNA viruses are those belonging to the picornaviridae family [2]. This family includes nine genera, some of which comprise major human pathogens, namely, Enterovirus (including Poliovirus, Coxsackievirus, Echovirus), Rhinovirus (approximately 105 serotypes), and Hepatovirus (Hepatitis A virus [HAV]). It is estimated that enteroviruses cause each year 10-15 million (or more) symptomatic infections [3]. The viruses in the Picornaviridae family cause an extraordinarily wide range of illnesses [4-7]. The syndromes associated with these agents include asymptomatic infection, aseptic meningitis syndrome (the most common acute viral disease of the CNS), colds, febrile illness with rash, conjunctivitis, herpangina, muscle infection, heart infection, and hepatitis. Human enterovirus 71 (EV71), a single-stranded, positivesense RNA virus, belongs to the Enterovirus genus of the Picornaviridae family. Picornavirus infections are among the most common viral infections in man [8]. Coxsackievirus B3 (CVB3) is an important human pathogen inducing acute and chronic viral myocarditis in children and young adults [9]. Quantitative structure activity relationship (QSAR) methods have been applied in numerous scientific disciplines such as computational drug design, predictive toxicology models, and high-throughput screening [10]. QSAR studies have been a major tool in drug optimization [11] and successful QSARs have been developed for ligands of uniform mode of action and congeneric chemical frameworks. A 2D QSAR technique is of particular interest since it eliminates the need for determining 3D structure, putative binding conformation, and molecular alignment [12]. A great number of structural molecular descriptors were explored using the stepwise multiple linear regression, replacement method and recently proposed enhanced replacement method to select the best subset of variables for
2D QSAR study. This approach is available in VLife Molecular Design Suite and takes advantage of interaction descriptors [13].

The present work was undertaken to find a correlation between physicochemical parameters and the biological activity from a series of 2-substituent-1H-benzimidazole-4-carboxamide derivatives against enteroviruses analogs. These correlations will be helpful in the development of benzimidazole-4-carboxamide as anti-enterovirus activities with increased therapeutic efficacy.

\section{Materials and Method}

A data set of thirty two compounds of 2-substituent- $1 \mathrm{H}$ benzimidazole-4-carboxamide for against enteroviruses activity was used for the present QSAR study [14]. The $\mathrm{IC}_{50}(\mu \mathrm{M})$ values reported in the literature were converted to negative logarithmic values to get $\mathrm{pIC}_{50}$ which were used for QSAR study. The structures of these inhibitors and their $\mathrm{pIC}_{50}$ values are given in Table 1. It insists as to select these series of compounds for our QSAR studies.

The structures of the compounds under study have been drawn in molecular design suite (MDS) 3.5. The drawn structures were then converted into $3 \mathrm{D}$ modules using the default conversion procedure implemented in the MDS. Energy minimizations were performed using Merck molecular force field (MMFF) and MMFF charge [15] followed by considering distance dependent dielectric constant of 1.0 and the convergence criterion of $0.01 \mathrm{kcal} / \mathrm{mol}$.

The sphere exclusion method [16] was adopted for division of training and test data set comprising of 26 and 6 molecules, respectively,

*Corresponding author: Mukesh C Sharma, School of Pharmacy, Devi Ahilya University, Takshila Campus, Khandwa Road, Indore-452 001, Madhya Pradesh, India, Tel: 91-731-216005; E-mail: mukeshcsharma@yahoo.com

Received March 11, 2015; Accepted April 17, 2015; Published April 22, 2015

Citation: Sharma MC (2015) Predictive Activity Modeling of 2-Substituent-1HBenzimidazole-4-Carboxamide Derivatives against Enteroviruses using QSAR Approach. J Health Med Informat 6: 187. doi:10.4172/2157-7420.1000187

Copyright: (c) 2015 Sharma MC. This is an open-access article distributed under the terms of the Creative Commons Attribution License, which permits unrestricted use, distribution, and reproduction in any medium, provided the original author and source are credited. 


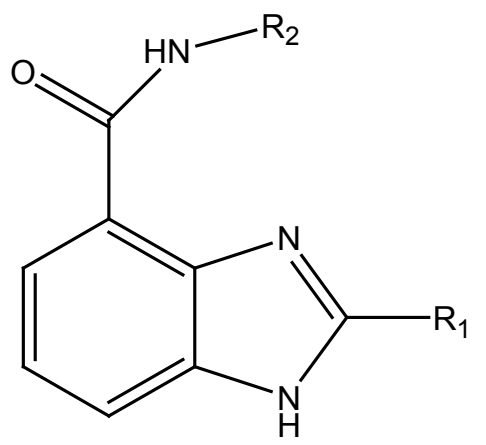

\begin{tabular}{|c|c|c|c|c|}
\hline S.No & R1 & R2 & $\left.\mathrm{IC}_{50}(\mu \mathrm{M})\right]$ & plC $_{50}$ \\
\hline 1 & & $\mathrm{H}$ & 30.6 & 4.5142 \\
\hline 2 & & $-\mathrm{CH}_{2} \mathrm{CH}_{2} \mathrm{OH}$ & 131 & 3.8827 \\
\hline 3 & & & 4.06 & 5.3914 \\
\hline 4 & & & 0.459 & 6.3381 \\
\hline 5 & & & 1.63 & 5.7878 \\
\hline 6 & & & 1.76 & 5.7544 \\
\hline
\end{tabular}




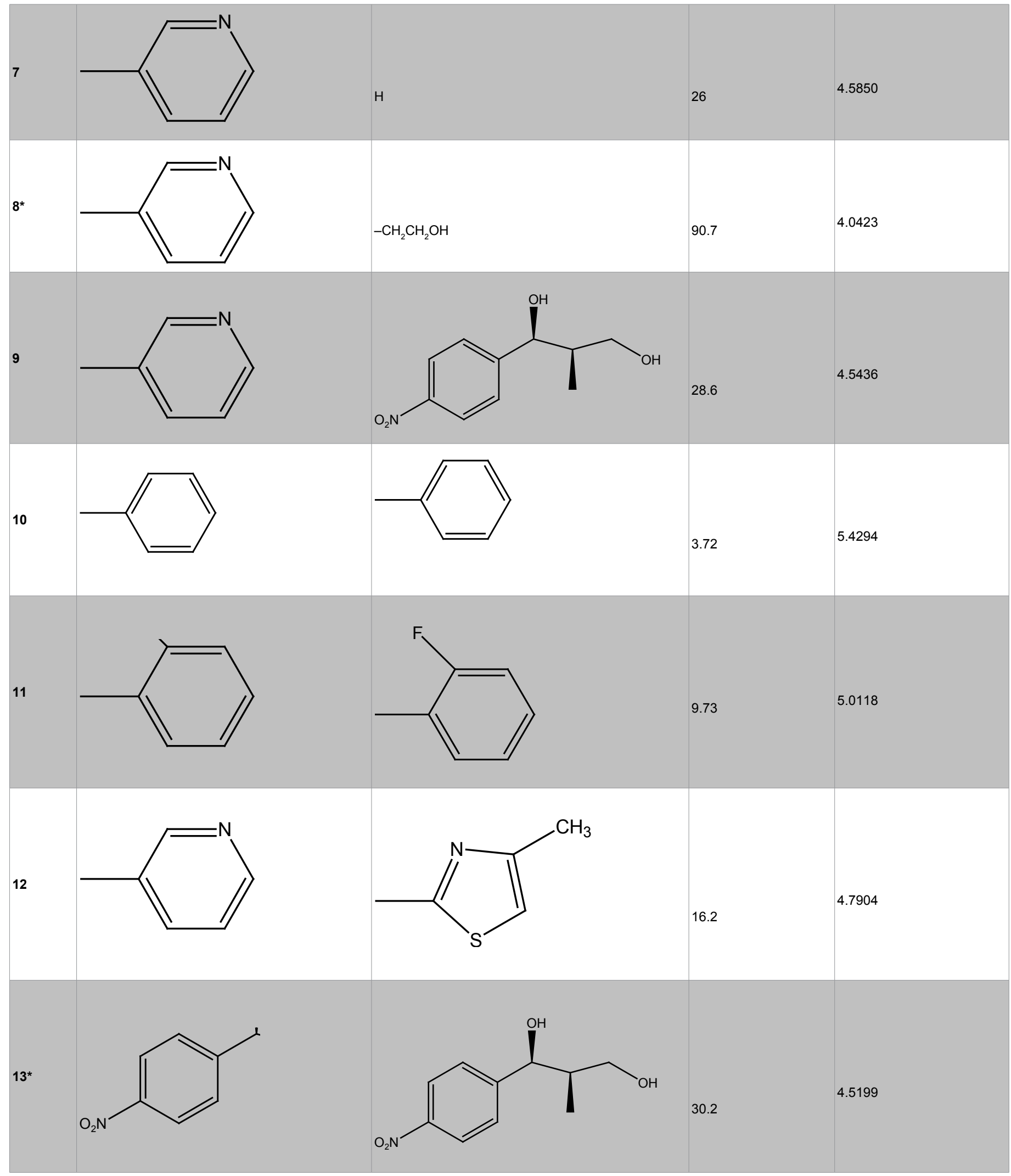


14

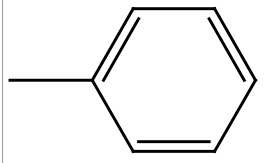

15

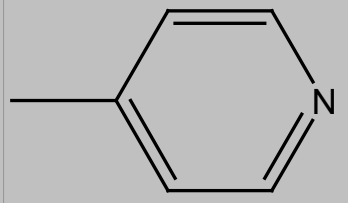

16

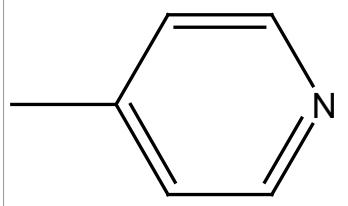

17

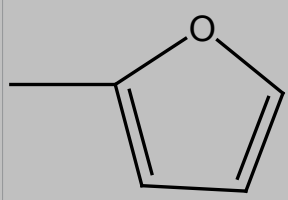

18<smiles>Cc1ccc([N+](=O)[O-])cc1</smiles>
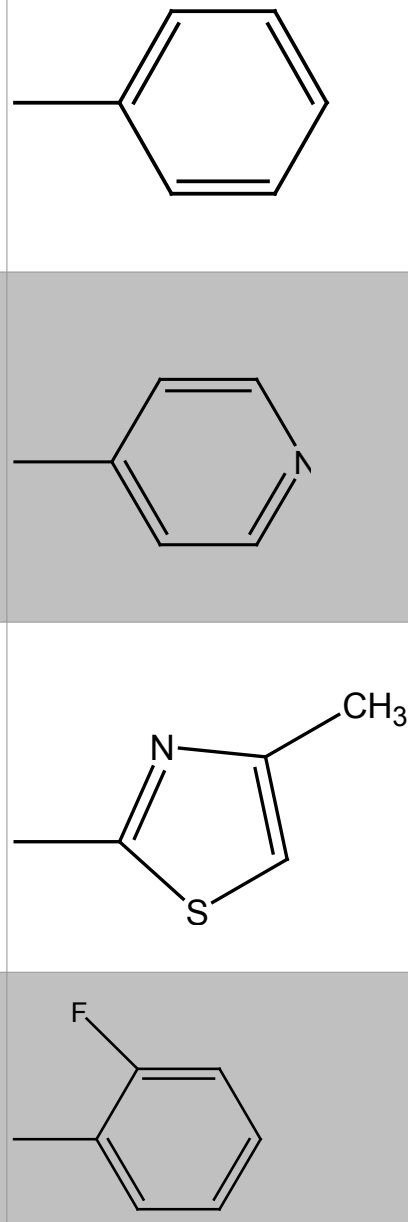<smiles>C[C@H](CO)[C@H](O)c1ccc([N+](=O)[O-])cc1</smiles>

3.3

12.3

37.2

21.3

37.7

4.4236

4.4294

4.6716

5.4814
20

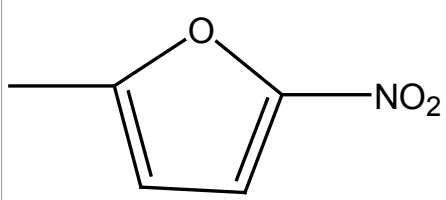

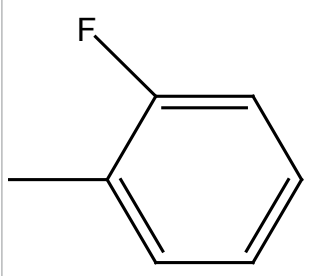

25.3 
21<smiles>CC(C)Cc1ccc([N+](=O)[O-])cc1</smiles><smiles>C[C@H](CO)[C@H](O)c1ccc([N+](=O)[O-])cc1</smiles>
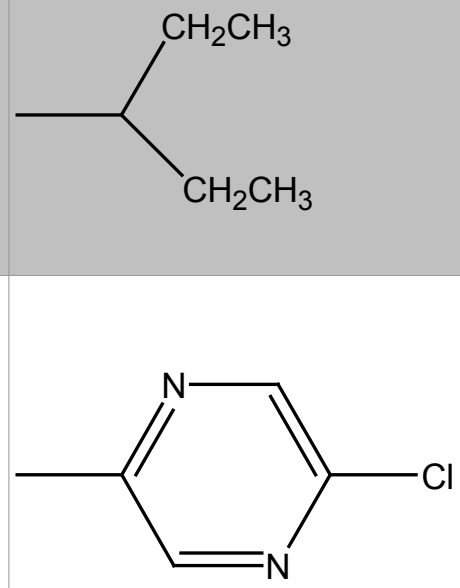

24

$25^{*}$

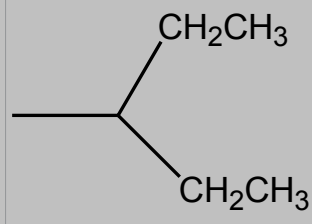

26

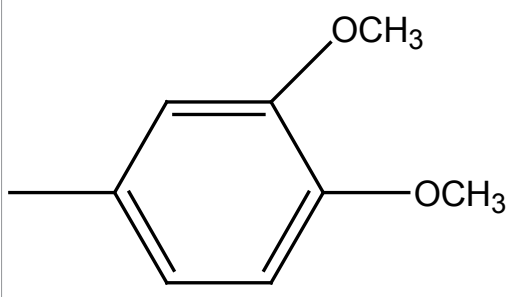

4.6401

4.7904

5.4559

4.7644

6.1549

4.7351 


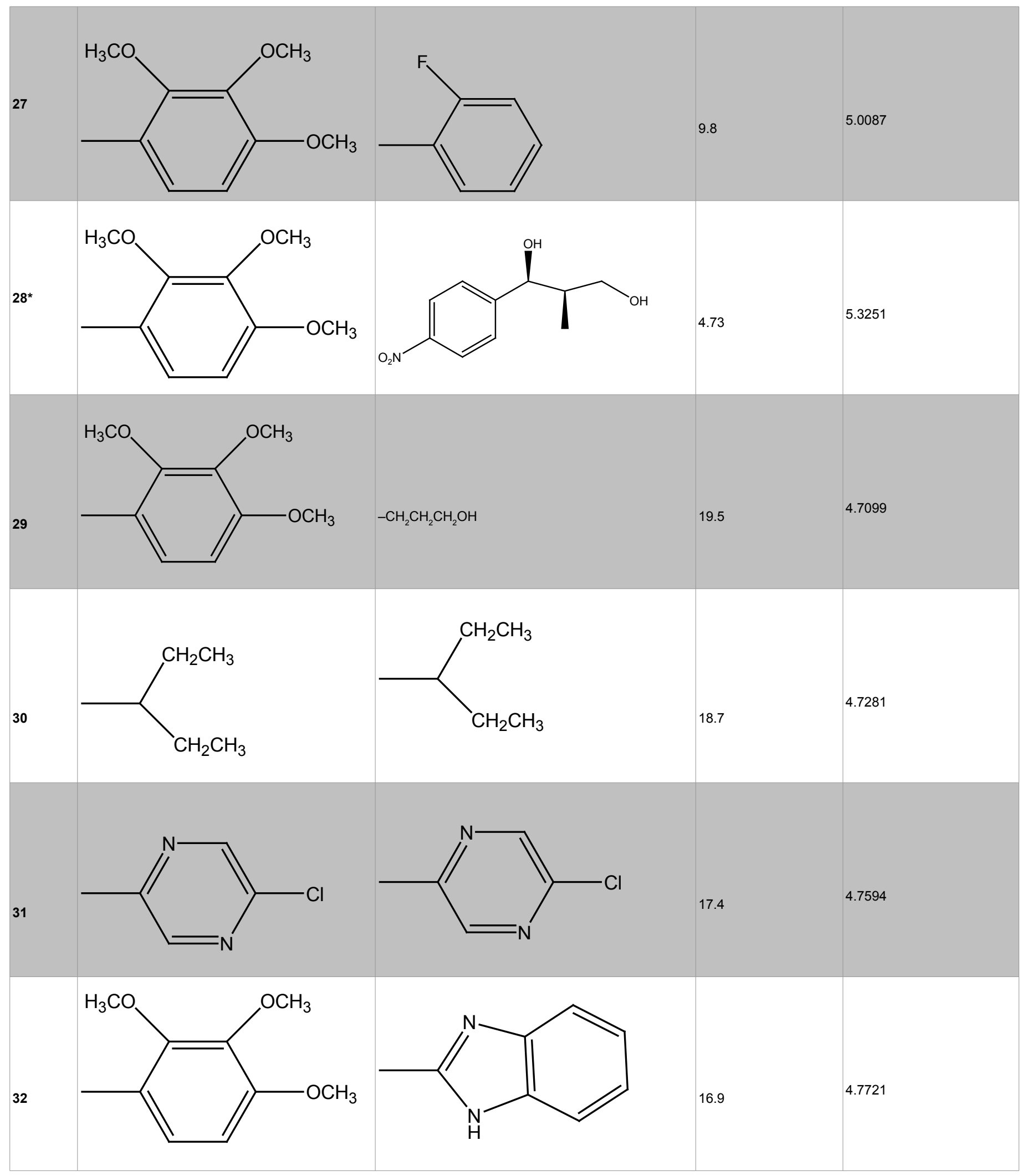

*Test compounds

Table 1: Structure, and biological activity of 2-substituent-1H-benzimidazole-4-carboxamide. 
with dissimilarity value of 2.9 where the dissimilarity value gives the sphere exclusion radius.

\section{Calculation of 2D descriptors}

The present study is an attempt to formulate QSAR modeling of 2-substituent-1H-benzimidazole-4-carboxamide compounds utilizing theoretical molecular descriptors such as $2 \mathrm{D}$ individual descriptors such as Mol. Wt., Volume, XlogP, smr; Estate Numbers, Estate contributions, Polar Surface Area Individual, Path count, Chain path count, Cluster, Path cluster, Kappa, Element Count, Estate number and Polar surface area electrostatic, constitutional, and geometrical, and topological indices calculated solely from the structures of these compounds. All the calculated 2D descriptors were considered as independent variable and biological activity as dependent variable.

A total of 230 descriptors were calculated by QSAR Plus module within VLife Sciences Molecular Design Suite. The descriptors having the same value or almost same value or highly correlated with other descriptors were removed initially, as they do not contribute to the QSAR.

\section{Results and Discussion}

In this study, QSAR equations are generated by multiple linear regression (MLR), and evaluated on the basis of various statistical terms like $\mathrm{r}^{2}$ (correlation coefficient), $\mathrm{q}^{2}$ (cross-validated correlation coefficient). 2D-QSAR equations were selected by optimizing the statistical results generated along with variation of the descriptors in these models.

$\mathrm{pIC}_{50}=0.6302( \pm 0.1722)$ T_C_N_4 $-0.8790( \pm 0.2915)$ Hydrogen count $+0.3705( \pm 0.0530)$ SaasN (Noxide) E-index $+0.5646( \pm 0.1618)$ SssOE-index

$$
\mathrm{N}_{\text {training }}=26, \mathrm{~N}_{\text {test }}=6, \mathrm{r}^{2}=0.7458, \mathrm{q}^{2}=0.7128 \text {, pred_ } \mathrm{r}^{2}=0.7092
$$

The model 1 with a coefficient of determination $\left(\mathrm{r}^{2}\right)=0.7458$ was considered, as the model showed an internal predictive power $\left(\mathrm{q}^{2}=0.7128\right)$ of $70 \%$ and a predictivity for the external test set (pred_ $\mathrm{r}^{2}=0.7092$ ) of about $70 \%$. The model indicates $\mathrm{H}$-count descriptor increased number of hydrogen molecule will result in increased anti-enteroviruses drug potency of benzimidazole-4-carboxamide derivatives. SaasN(Noxide)E- indices for number of nitro-oxide group connected with two aromatic and one single bond, contributed positively and is detrimental to biologic activity in the aforementioned model at the R1, and R2 position. T_C_N_4 (count of number of carbon atoms separated from any nitrogen atom by 4 bonds) descriptor influencing activity variation. SssOE-index showed positive contribution indicated that the anti-enteroviruses drug was increased with the presence of methoxy groups of fragment R1 may lead to an increase in the activity. The correlation matrix between the physico-chemical parameters and the biological activity is presented in Table 2 . The observed activity and predicted activity $\mathrm{pIC}_{50}$ along with residual values are shown in Table 3.The contribution chart and plots of observed vs. predicted values of $\mathrm{pIC}_{50}$ are shown in Figures 1a and $1 \mathrm{~b}$ respectively.

$\mathrm{pIC}_{50}=-0.482( \pm 0.125) \quad$ Polarizability $\mathrm{AHC}+0.217( \pm 0.062)$

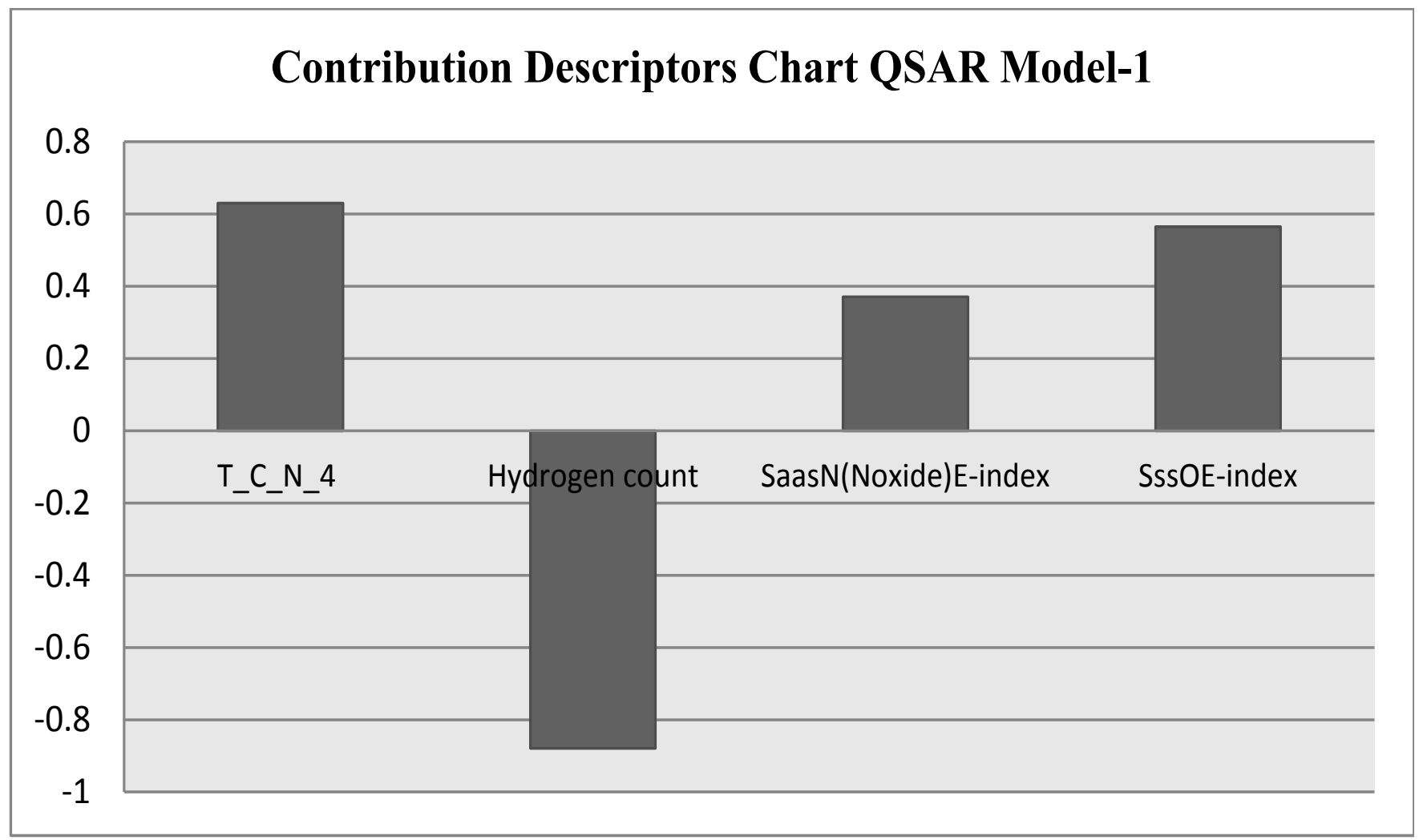

Figure 1a: Plot of contribution chart of 2D QSAR model. 


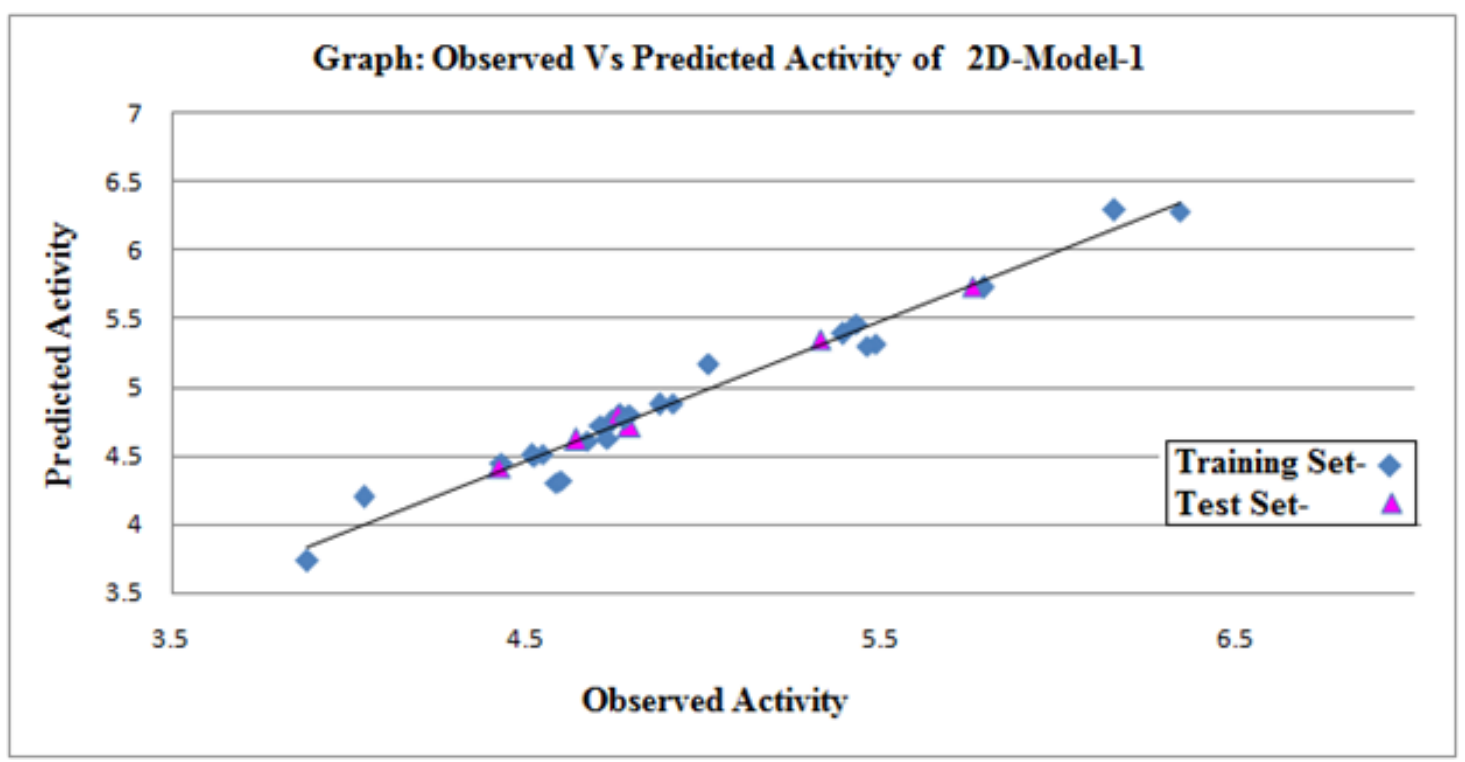

Figure 1b: Graphs of observed vs. predicted activity of 2D QSAR model -1.

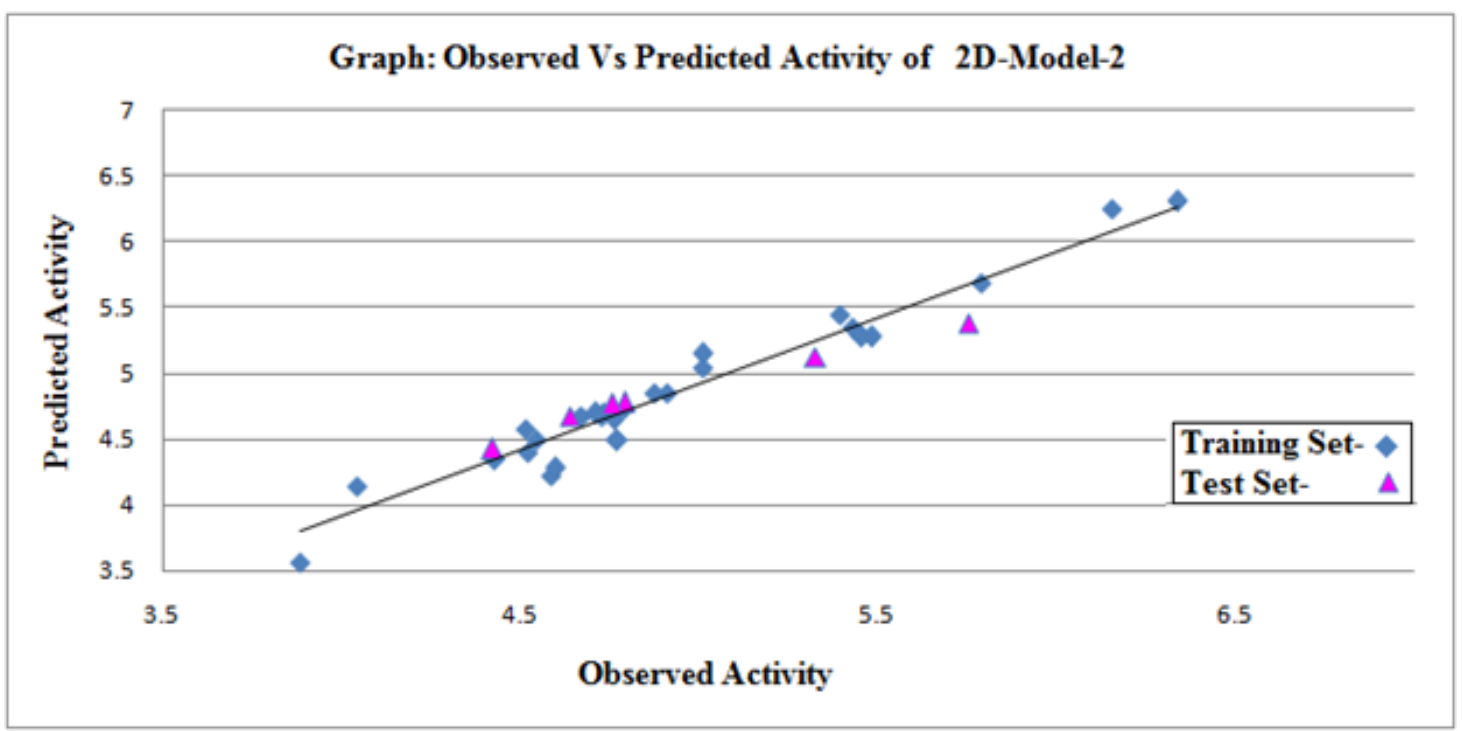

Figure1c: Graphs of observed vs. predicted activity of 2D QSAR model -2 .

\begin{tabular}{|c|c|c|c|}
\hline Parameter & T_C_N_4 & Hydrogen count & SaasN(Noxide)E-index \\
\hline T_C_N_4 & 1.0000 & \\
\hline Hydrogen count & 0.2165 & 1.0000 & 1.0000 \\
\hline SaasN(Noxide)E-index & 0.4128 & 0.5395 & 0.8041 \\
\hline SssOE-index & 0.5914 & 0.6873 & 1.0000 \\
\hline
\end{tabular}

Table 2: Correlation matrix between descriptors present in the best QSAR model -1. 
Citation: Sharma MC (2015) Predictive Activity Modeling of 2-Substituent-1H-Benzimidazole-4-Carboxamide Derivatives against Enteroviruses using QSAR Approach. J Health Med Informat 6: 187. doi:10.4172/2157-7420.1000187

Page 9 of 11

\section{H-Acceptor Count}

$\mathrm{N}_{\text {training }}=26, \mathrm{~N}_{\text {test }}=6, \mathrm{r}^{2}=0.7194, \mathrm{q}^{2}=0.6732, \mathrm{~F}$ test $=18.2403$, pred $\mathrm{r}^{2}=0.6538$

The same data set subjected to the method resulted in $\mathrm{r}^{2}$ of 0.7194 and $\mathrm{q}^{2}$ of $67 \%$, with pred_r $\mathrm{r}^{2}$ of $65 \%$. The PolarizabilityAHC descriptor signifies the molecular polarizability using sum of atomic polarizabilities using the atomic hybrid components (AHC) and negative coefficient in the model, suggesting that the increased polarizable groups in the molecules have significant activity on the anti-enteroviruses drug. The descriptor H-Acceptor count explains the number of hydrogen bond acceptor groups present in the molecules. The plots of observed vs. predicted values of $\mathrm{pIC}_{50}$ are shown in Figure 1c. index

$\mathrm{pIC}_{50}=0.4375( \pm 0.1434) \mathrm{SsCH}_{3}$ count $+0.3370( \pm 0.1590)$ SsOHE-

$\mathrm{N}_{\text {training }}=26, \mathrm{~N}_{\text {test }}=6, \mathrm{r}^{2}=0.7194, \mathrm{q}^{2}=0.6882, \mathrm{~F}$ test $=13.468$, pred $\mathrm{r}^{2}=0.6102$

Model 3 with the same data set was performed, which resulted in a coefficient of correlation of 0.7494 and external predictivity of $61 \%$. The developed regression model-3 reveals that the descriptor SsOHE-index which is topological state indices for number of $-\mathrm{OH}$ group connected with one single bond at R1 substitution site is inversely proportional to activity which means that branching with hydroxyl atom is detrimental for activity. $\mathrm{SsCH}_{3}$ count positive coefficient of this descriptor signifies the importance of methyl group for activity. The above all models are validated by predicting the biological activities of the training and test molecules, as indicated in Table 3. The plots of observed vs. predicted values of $\mathrm{pIC}_{50}$ are shown in Figure 1d.

\section{Conclusion}

Here, we show that the quantitative structure-activity relationship (QSAR) method commonly used to predict the physicochemical properties of chemical compounds can be applied to predict the toxicity of benzimidazole analogues as anti-enteroviruses drug. The models reliably predict the toxicity of all considered compounds, and the methodology is expected to provide guidance for the future design of safe anti-enteroviruses agents. On the basis of discussion given earlier we could conclude that benzimidazole analogues must have T_C_N_4, SaasN (Noxide) E-index and SssOE-index values for enhanced inhibition activity. Talking about the effects of the SssOEindex on the bioactivity of derivatives of benzimidazole analogues, the developed QSAR model suggests that a positive SssOE-index will definitely be favorable to the activity. The suggested substitutions are $-\mathrm{CH}_{3},-\mathrm{OH}$, methoxy and two substitutions simultaneously at R1- and R2- positions for the improved and potent anti-enterovirus activities. We hope that the current study provides better insight into the designing and development of more potent benzimidazole-4carboxamide inhibitors as anti-enterovirus drug in the future.

\section{Acknowledgements}

The authors are grateful to VLife Sciences Technologies, Pune, India, for providing them trial version VLlife MDS 3.5 software. Author are thankful to the University Grants Commission (UGC), New Delhi for awarding a Research Award No. F. 30-1/2013(SA-II)/RA-2012-14-NEW-GE-MAD-4200.

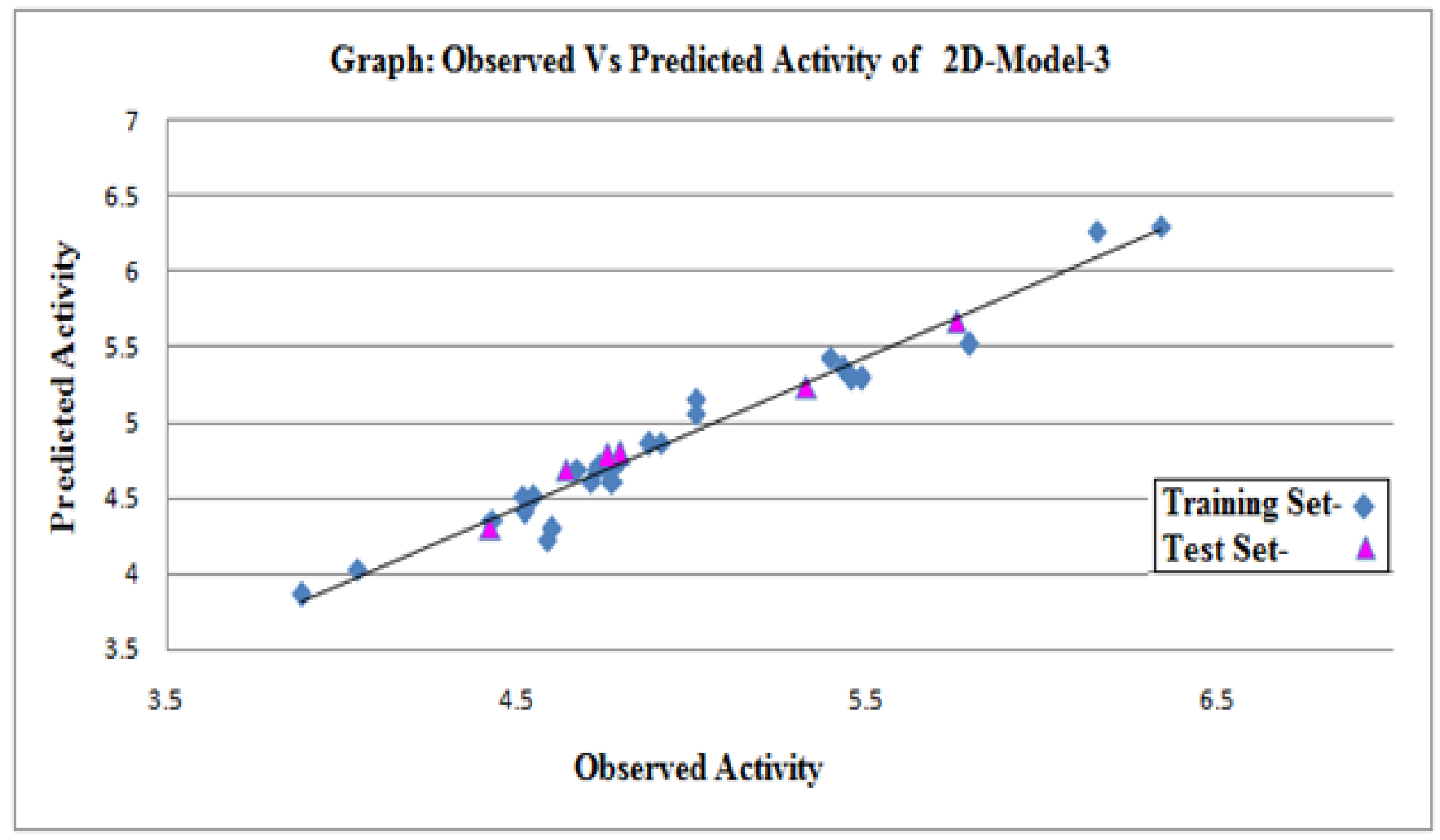

Figure 1d: Graphs of observed vs. predicted activity of 2D QSAR model -3. 
Citation: Sharma MC (2015) Predictive Activity Modeling of 2-Substituent-1H-Benzimidazole-4-Carboxamide Derivatives against Enteroviruses using QSAR Approach. J Health Med Informat 6: 187. doi:10.4172/2157-7420.1000187

Page 10 of 11

\begin{tabular}{|c|c|c|c|c|c|c|c|}
\hline \multirow{2}{*}{ Com. } & \multirow{2}{*}{$\mathrm{plC}_{50}$} & \multicolumn{2}{|c|}{ 2D QSAR Model-1 } & \multicolumn{2}{|c|}{ 2D QSAR model-2 } & \multicolumn{2}{|c|}{ 2D QSAR model-3 } \\
\hline & & Pred. & Res. & Pred. & Res. & Pred. & Res. \\
\hline 1 & 4.5142 & 4.5025 & 0.0117 & 4.5760 & -0.0618 & 4.5071 & 0.0071 \\
\hline 2 & 3.8827 & 3.7289 & 0.1538 & 3.5602 & 0.3225 & 3.8565 & 0.0262 \\
\hline 3 & 5.3914 & 5.3884 & 0.003 & 5.4473 & -0.0559 & 5.4269 & -0.0355 \\
\hline 4 & 6.3381 & 6.2834 & 0.0547 & 6.3064 & 0.0317 & 6.3004 & 0.0377 \\
\hline 5 & 5.7878 & 5.7266 & 0.0612 & 5.6906 & 0.0972 & 5.5156 & 0.2722 \\
\hline 6 & 5.7544 & 5.7311 & 0.0233 & 5.3742 & 0.3802 & 5.6645 & 0.0899 \\
\hline 7 & 4.585 & 4.3007 & 0.2843 & 4.2214 & 0.3636 & 4.2154 & 0.3696 \\
\hline 8 & 4.0423 & 4.198 & -0.1557 & 4.1349 & -0.0926 & 4.0298 & 0.0125 \\
\hline 9 & 4.5436 & 4.5063 & 0.0373 & 4.4956 & 0.048 & 4.5016 & 0.042 \\
\hline 10 & 5.4294 & 5.4625 & -0.0331 & 5.3463 & 0.0831 & 5.3545 & 0.0749 \\
\hline 11 & 5.0118 & 5.167 & -0.1552 & 5.1459 & -0.1341 & 5.1551 & -0.1433 \\
\hline 12 & 4.7904 & 4.7947 & -0.0043 & 4.7327 & 0.0577 & 4.7427 & 0.0477 \\
\hline 13 & 4.5199 & 4.4922 & 0.0277 & 4.3954 & 0.1245 & 4.4066 & 0.1133 \\
\hline 14 & 4.91 & 4.8786 & 0.0314 & 4.8533 & 0.0567 & 4.8641 & 0.0459 \\
\hline 15 & 4.4294 & 4.4415 & -0.0121 & 4.3402 & 0.0892 & 4.3485 & 0.0809 \\
\hline 16 & 4.6716 & 4.6075 & 0.0641 & 4.6685 & 0.0031 & 4.6838 & -0.0122 \\
\hline 17 & 5.4814 & 5.318 & 0.1634 & 5.2743 & 0.2071 & 5.2891 & 0.1923 \\
\hline 18 & 4.4236 & 4.4157 & 0.0079 & 4.4208 & 0.0028 & 4.296 & 0.1276 \\
\hline 19 & 4.8728 & 4.8718 & 0.001 & 4.8432 & 0.0296 & 4.8571 & 0.0157 \\
\hline 20 & 4.5968 & 4.3168 & 0.28 & 4.2768 & 0.32 & 4.2922 & 0.3046 \\
\hline
\end{tabular}


Citation: Sharma MC (2015) Predictive Activity Modeling of 2-Substituent-1H-Benzimidazole-4-Carboxamide Derivatives against Enteroviruses using QSAR Approach. J Health Med Informat 6: 187. doi:10.4172/2157-7420.1000187

Page 11 of 11

\begin{tabular}{|c|c|c|c|c|c|c|c|}
\hline 21 & 4.6401 & 4.6168 & 0.0233 & 4.6745 & -0.0344 & 4.6896 & -0.0495 \\
\hline 22 & 4.7904 & 4.713 & 0.0774 & 4.777 & 0.0134 & 4.7922 & -0.0018 \\
\hline 23 & 5.4559 & 5.3027 & 0.1532 & 5.2753 & 0.1806 & 5.2891 & 0.1668 \\
\hline 24 & 4.7644 & 4.7937 & -0.0293 & 4.6479 & 0.1165 & 4.6622 & 0.1022 \\
\hline 25 & 6.1549 & 6.2882 & -0.1333 & 6.2505 & -0.0956 & 6.2649 & -0.11 \\
\hline 26 & 4.7351 & 4.7429 & -0.0078 & 4.7058 & 0.0293 & 4.7216 & 0.0135 \\
\hline 27 & 5.0087 & 5.1679 & -0.1592 & 5.042 & -0.0333 & 5.055 & -0.0463 \\
\hline 28 & 5.3251 & 5.3506 & -0.0255 & 5.1184 & 0.2067 & 5.2311 & 0.094 \\
\hline 29 & 4.7099 & 4.7151 & -0.0052 & 4.6927 & 0.0172 & 4.6025 & 0.1074 \\
\hline 30 & 4.7281 & 4.6212 & 0.1069 & 4.675 & 0.0531 & 4.6914 & 0.0367 \\
\hline 31 & 4.7594 & 4.7977 & -0.0383 & 4.7604 & -0.001 & 4.7762 & -0.0168 \\
\hline 32 & 4.7721 & 4.7702 & 0.0019 & 4.4842 & 0.2879 & 4.6009 & 0.1712 \\
\hline
\end{tabular}

Table 3: Predicted activities according to QSAR models results of 2-substituent-1H-benzimidazole-4-carboxamide.

\section{Reference}

1. Merkle I, van Ooij MJ, van Kuppeveld FJ, Glaudemans DH, Galama JM, et al (2002) Biological significance of a human enterovirus B-specific RNA element in the 3' nontranslated region. J Virol 76: 9900-9909.

2. Santti J, Harvala H, Kinnunen L, Hyypiä T (2000) Molecular epidemiology and evolution of coxsackievirus A9. J Gen Virol 81: 1361-1372.

3. Rotbart HA (2002) Treatment of picornavirus infections. Antiviral Res 53: 83-98

4. Melnick JL (1983) Portraits of viruses: The picornaviruses. Intervirology 20 61-100.

5. Melnick JL (1996) Enteroviruses: Polioviruses, Coxsackieviruses, Echoviruses, and Newer Enteroviruses. In: Knipe BN, Howley DM, Chanock PM, Melnick RM, Monath JL et al. (eds.) Fields Virology. Lippincott-Raven, Philadelphia.

6. Melnick JL (1992) Properties and classification of hepatitis A virus Vaccine 10 S24-S26.

7. Rueckert RR (1990) Picornaviruses and their replication. In: Channock RM Hirsch, Melnick MS, Monath JL, Roizman TPB (eds.) Fields Virology (2ndedn.) Raven Press, New York, USA.

8. Cutrí CC, Garozzo A, Siracusa MA, Sarvá MC, Tempera G, et al. (1998) Synthesis and Antiviral Activity of a New Series of 4-Isothiazolecarbonitriles. Bioorg Med Chem 6: 2271-2280.

9. Mason J W (2003) Myocarditis and dilated cardiomyopathy: an inflammatory link. Cardiovasc Res 60: 5-10

10. Gasteiger J and Engel T (2003) Chemoinformatics: A Textbook. Wiley-VCH Weinheim.

11. Hansch C, Fujita $T$ (1964) $p-\sigma-\pi$ analysis. A method for the correlation of biological activity and chemical structure. J Am Chem Soc 86: 1616-1626.
12. Gupta SP, Mathur AN, Naggapa AN, Kumar D, Kumaran S (2003) A quantitative structure-activity relationship study on a novel class of calcium entry blockers: 1-[\{4-(aminoalkoxy)phenylsulfonyl] indolizines. Eur J Med Chem 38: 867-873.

13. Vlife MDS software package, version 3.5 (2008) Vlifescience technologies Pvt Ltd, Pune.

14. Xue F, Luo X, Ye C, Ye W, Wang Y (2011) Inhibitory properties of 2-substituent$1 \mathrm{H}$-benzimidazole-4-carboxamide derivatives against enteroviruses. Bioorg Med Chem 19: 2641-2649.

15. Halgren TA (1996) Merck molecular force field. III. Molecular geometries and vibrational frequencies for MMFF94. J Comput Chem 17: 553-586.

16. Golbraikh A,Tropsha A (2002) Predictive QSAR modeling based on diversity sampling of experimental datasets for the training and test set selection. J Comput Aided Mol Des 16: 357-369. 